\title{
Organisational Paradigms and Network Centric Organisations
}

\author{
Irena Ali, Leoni Warne, and Derek Bopping \\ Defence Science and Technology Organisation, \\ Canberra, Australia
}

Irena.ali@dsto.defence.gov.au leoni.warne@dsto.defence.gov.au derek.bopping@dsto.defence.gov.au

\section{Dennis Hart \\ Australian National University, Canberra, Australia}

\author{
dennis.hart@anu.edu.au
}

\author{
Celina Pascoe \\ University of Canberra, \\ Canberra, Australia
}

\begin{abstract}
Many organizations grapple with uncertainty and vagaries of economic and political climate. A number of companies attained dramatic competitive advantages in their fields by creating comprehensive, complex communication and information networks. These companies, facilitated by the increasing efficiencies and speed of information technology, remained flexible and adaptable to change by working in a network centric way. Much of the network centric (NC) related work done to date has been mainly in the technological domain. This paper focuses on the human and organizational factors that need to be considered to make the most of the future network centric warfare (NCW) and enable future warfighters to deal with war, peace, terrorism and overall uncertainty. Particular focus is placed on the issues that individuals and groups face in the NC environment. Such issues include: organizational culture, cognitive demands, and knowledge mobilization and learning.
\end{abstract}

Keywords: network centric organizations, teamwork, organizational culture, communication climate, collaboration and cooperation

\section{Introduction}

During the '90s, a number of companies attained dramatic competitive advantages in their fields by creating comprehensive, complex communication and information networks. These companies, facilitated by the increasing efficiencies and speed of information technology, remained

Material published as part of this journal, either on-line or in print, is copyrighted by Informing Science. Permission to make digital or paper copy of part or all of these works for personal or classroom use is granted without fee provided that the copies are not made or distributed for profit or commercial advantage AND that copies 1) bear this notice in full and 2) give the full citation on the first page. It is permissible to abstract these works so long as credit is given. To copy in all other cases or to republish or to post on a server or to redistribute to lists requires specific permission from the publisher at Publisher@InformingScience.org flexible and adaptable to change. Information and communication technologies (ICT) now pervade virtually all areas of modern society, civil and military. The Internet has connected people and organizations across the world in a way never seen before and the implications for this new connectivity are still being played out and 
remain to be fully understood. This technology helped companies to make accurate predictions, minimize risk, and adapt rapidly to dynamic circumstances. NCW is the application of this concept to the military. In the military sphere, the term 'network centric warfare' or NCW has emerged as the umbrella under which the implications of ICT and the connectivity it enables for military operations and organization are argued and assessed. The challenge in this application is to define the ways in which the competitive advantage gained by networked companies can be translated to 'combat advantage' (ADF, 2003).

The authors just began a research study into the human dimension of future warfighting. The research will span over two years and involves a multidisciplinary team of researchers whose specialty range from information systems, through to psychology, education, organizational communication, and the information usage and its impact on decision making. The data will be gathered using both qualitative and quantitative methods as well as experimentation and simulation. This paper is mainly based on an extensive literature review the authors have conducted. There are a number of reoccurring themes that emerged which are applicable to organizations wanting to enhance their way of doing business and some of these issues are discussed below.

\section{The Organizational Context for Network Centricity}

New organizational forms that are horizontal rather than functional or vertical are referred to, variously, as: modular, cluster, learning, network, or perpetual matrix organizations, spinout or virtual corporations (Quinn, 1992; Senge, 1990). Regardless of the name, the defining characteristics of these new organizational forms are flatter hierarchies; decentralized decision-making; greater capacity for tolerance of ambiguity; permeable internal and external boundaries; empowerment of employees; capacity for renewal; self-organizing units, and self-integrating coordination mechanisms (Daft \& Lewin, 1993).

In such organizations knowledge is the most strategically important resource and organizational capabilities are the product of distinctive competencies in integrating and applying this knowledge. Thus communication based on sharing of knowledge is the pervasive, underlying force responsible for maintenance and dissemination of strategic capabilities. Tucker, Meyer, and Westerman (1996) point out that strategic capabilities result from new knowledge creation accomplished through a combination of individuals' tacit and objective knowledge, yet this collection of knowledge must somehow be aggregated and communicated at a collective level.

\section{The Social and Human Influences in the Network Centric Environment}

As noted earlier, the network construct was necessitated by the growing rates of change and environmental complexity in which organizations operate. Dealing with these complex problems requires the development of flexible organizational structures (Bovasso, 1992; Chisholm, 1996). Such organizational structures are intended to comprise a dynamic system of networks that maximize information exchange between members. In a network organization, informal social networks should spontaneously emerge in response to a given situation and supersede formal organizational structures, such as those depicted in organizational charts. These networks may involve members, or parties, from different sectors and different levels. This decentralization of hierarchy is supposed to facilitate a prudent response to unplanned circumstances and offer diverse perspectives on problems through all the available expertise within the network. More importantly, its members, not a centralized source or power, control the network organization.

Much of the NCW discussions are based around technology. But, in the context of NCW no less than other technologies, the addition of a new technological capability on the assumption that existing organizational structures, procedures and processes will be able to seamlessly incorporate 
and make use of it, is at least potentially, a mistake. Conversely, the opposite assumption that any organizational and human changes needed to take advantage of new technological capability will always be achievable, is almost certainly equally reckless. Working effectively in the network centric environment requires effective teamwork based on cooperation, collaboration, trust, and mobilizing organizational as well as individual knowledge.

\section{Issues for Individuals and Groups in Network Centric Environment}

A major emerging trend in organizational contexts is a lessened focus on routine and greater demands for intense engagement and communication. There is an increased requirement to engage more intensely in managing, interpreting and sharing large amounts of information and a demand for rapid and coordinated group decision -making. This, in turn, places far greater cognitive demands on individuals, their personal initiative, learning and communicating, and often intuitively based problem-solving capabilities (Crawford, 2003).

\section{Communication Climate}

Communication is an essential element of all collective human activity. It facilitates learning, it helps build effective teams and it contributes to the development of individual knowledge bases. The objective of a network centric environment is to maximize the usefulness of information and expertise held by different parties within a group. Traditionally and historically, people have disseminated information through one-on-one processes. In contrast, a network centric operation permits instant distribution and utilization of information to everyone in a network, regardless of proximity. However, meaningful dissemination of information depends on people's willingness to share and receive information. In this relationship of interdependencies, communication and trust play vital roles.

The overall organizational climate is greatly influenced by the prevailing communication behaviors. Organizational climate can be described as the 'internal social psychological environment' or the 'shared, holistic, collectively defined social context' that has emerged within the organization over time (Denison, 1996). There is evidence that the more favorably perceived the climate is, the higher will be levels of organizational commitment.

The literature on communication differentiates between supportive and defensive communication climates. Supportive climates are characterized by open exchanges of information and the use of constructive conflict management procedures, and an overall culture of interacting in a confirming and cooperative manner. In the network centric organization, communication climate is important because of its impact on information sharing, and openness, generally, and on organizational members' levels of commitment to the organization (Guzley, 1992).

\section{Social Learning}

In work life, socially-based learning occurs all the time and in ways not often recognized as learning Jordan (1996). "Situated learning" refers to the learning that occurs from the interactions between people and the environment Lave \& Wenger (1991) while "social learning" is a more applied concept and refers to the learning that occurs within a group, an organisation, or any cultural cluster and it includes:

- the procedures that facilitate generative learning - learning that enhances the enterprise's ability to adjust to dynamic and unexpected situations and to react creatively to them; and

- the procedures by which knowledge and practice are transmitted across posting cycles, throughout time and across different work situations (Ali, Pascoe, \& Warne, 2002) 
From a cultural perspective, social learning is enabled by consistent, guided enculturation leading to a common identity with a common language, a shared vision and shared objectives facilitating information and knowledge sharing, which is built on trust. To maintain this supportive culture requires strong, but nurturing leadership, an open and supportive communication climate, and conditions of service, which can be seen as the organization's reciprocal loyalty to its staff.

An NCW environment entails the interaction of multiple and diverse groups and individuals who need to successfully learn from each other in order to cope with the demands placed upon them. Therefore, an understanding of the issues involved in such learning is an important aspect impacting the success of NCW operations.

\section{Interaction Management and Knowledge Mobilization}

In complex situations of rapid and often high-risk change, such as are often encountered in military operations, effective knowledge management and knowledge mobilization may be a matter of life and death. The discussions above suggest that effectiveness can be improved in a NCW environment through purposeful steps to:

- acknowledge and respect the different needs and capabilities of people with diverse styles and temperaments;

- recognize that the people with different styles will be enabled to a different extent by any 'one size fits all' technical environment;

- recognize that technical tools are more rigid in carrying out routines than the people who formerly carried out such tasks - ensure automated machine based operations are also investigated and reviewed as well as human performance;

- recognize the new demands of more complex socio-technical settings in which people operate and the new capabilities that will be strategic assets to any team;

- create, make explicit and support rules, roles and patterns of authority and responsibility that are appropriate to the kinds of thinking and informal learning required by all people in complex and changing contexts;

- promote rapid mobilization of shared knowledge;

- in complex and/or changing contexts, enhance opportunities for people to communicate, debate, critique, question, co-invent, experiment and critically evaluate and modify provisional solutions;

- engage in reflection and review about the strategic effectiveness of the evolving patterns of activity, and deployment of human capabilities of different kinds, and the match between these and the demands of the evolving context;

- recognize that many people will need to actively share in the decision making and negotiations around complex evolving activities to develop and strengthen their new capabilities and to identify with the strategic purpose of the new kinds of thinking, learning and communication (Crawford, 2003).

\section{Cooperation and Collaboration}

A common feature of complex military operations is the involvement of a range of multinational forces and, in addition, other government and humanitarian agencies. Each agency or force brings its own culture, philosophy, goals, practices and skills to the crisis, and the challenge becomes finding a way to synchronize everyone's efforts. 
It has been argued that "Collaboration is essential to shared situational awareness because it allows widely dispersed people to use their battlespace awareness for mutual advantage. It also allows people to make, and make use of, expert contributions to analysis and decision -making. It involves a shift from sequential planning activities to an ongoing interaction between different levels, thus saving time and providing opportunities for ideas to move across boundaries. Network connectivity is important for providing the technical means that will assist collaboration, but the quality of our people will be more important" (Australian Defence Force, 2003).

However important the technology is for cooperation and collaboration in the network centric environment, information and networking alone are not substitutes for cooperation and collaboration based on common goals, common identity, mutual trust, doctrine that reflect these values and sharing of information. In fact, sharing of information lies at the core of NCW. Sharing has an organizational, a behavioral, and a technical component. While the technical component enables, the organizational and behavioral components generate value.

\section{Trust}

Effective and efficient exchange of information underpins the success of all military activities. Without such exchange, the collective action and cooperation necessary for the accomplishment of military goals, particularly in operational contexts, is impossible. However, effective information exchange in a warfighting context is often more difficult than it first appears. Factors can emerge which obstruct an individual's willingness to volunteer information or to provide it to others on request, particularly when the information of concern is highly sensitive and when the potential recipient is largely unknown. Concerns over how others might use valuable information often restricts one's readiness to part with it (Erickson, 1979).

A large amount of research has demonstrated that the extent to which an individual trusts another has a significant impact on their willingness to exchange valuable information with others (Ericson, 1979). Despite this extensive empirical attention, consensus on a definition of trust has not been forthcoming (Barber, 1983; Kramer, 1999). For present purposes, trust can be defined as the subjective expectation of positive treatment under conditions of vulnerability. In other words, we trust another to the extent that we believe they will act beneficially (or at least not detrimentally) towards us if we choose to engage them in some form of cooperation and when cooperating involves some degree of risk (Gambetta, 1988). Thus, trust is especially relevant when there is uncertainty or ignorance as to the motives and actions of others. When these can be predicted with absolute certainty, trust is not required. When they cannot, as in most 'real world' circumstances, a degree of trust is necessary to make human action and interaction possible.

\section{Teamwork}

Teamwork is essential to the success of any organization and it is more so in a network centric environment. Within this context, it is useful to understand the difference between the terms 'team' and 'teamwork', and to recognize that the concepts captured by both terms are prerequisites for productive collaborative work. 'Teamwork' means an individual is accountable, it means sharing information, and working better together. On the other hand, in a 'team' everybody holds themselves and each other accountable and performance is measured against collective output (Drucker, 1999a, 1999b). Teamwork is a skill and the lack of it can be a barrier to effective performance.

Bowman and Pierce (2003) conducted research aimed to delineate and better understand the cultural barriers to teamwork. They identified several cultural barriers to teamwork, cognitive and organizational. They found that culture (understood as patterns and deeply felt values that are shared across an organization and which drive behaviors and performance) influenced cognitive 
fundamentals of teamwork, such as communication, coordination, and decision-making. Culture also influenced the organizational barriers, through rules and procedures for training and personnel selection.

The implications of that research are that it is important to understand how the cultural and organizational dimensions affect teamwork in order to be able to develop training tools to help leaders and teams to overcome these possible barriers. It is easy to misinterpret the actions of another team member, based on an incomplete or incorrect understanding of that person's cognitive style. This is of particular importance in the NCW and in the NC environment in general, as there may never be an opportunity to establish personal, face-to-face relationships and pick up on nonverbal cues. Also, learning that some individuals prefer more or less detail in a task, or more or less group interaction, or are more or less willing to approach a higher-ranking officer could be a simple and cost-effective way of improving team dynamics. Therefore, people working in NC environment must rely on their intuition and other cues while dealing with team members at the other end of a network.

\section{Social Cohesion and Common Identity}

Based on the authors' previous studies into Social Learning (Ali et al., 2002;Warne, Ali, \& Pascoe, 2003) a common identity is one of the most important factors in developing social cohesion, teamwork as well as an enabler of social learning. Common identity requires a shift from seeing ourselves as separate to seeing ourselves as connected to, and part of, an organization or organizational sub-unit. This shift in thinking is correlated with a strengthening of common identity. This common identity is influenced by the extent of cultural cohesion, shared goals and shared understanding and is characterized by loyalty and trust among members of the organization.

Each cognitive domain is fully personal, private and so the same situations, the same information may lead to different perceptions with different persons. Even the same words may have different meaning for different people. This is because their interpreting of information, based on education, past experiences, etc, always differs to some degree. However, insofar as different people belong to a common group or work in a similar context, they share, to some extent, a common identity that can reduce this discrepancy. This is an important issue in NCW because the core effort is to develop and distribute superior situational awareness, common understanding of the commander's intent, and common identity to synchronize operations and activities (Ahvenainen, 2003).

\section{Conclusion}

An effective and enduring learning and knowledge development climate is an essential element of the network centric environment. It is not a program, it is a process which requires doctrinal, cultural, educational as well as changes to recruitment and training policies. Such changes require a supportive organizational context for interaction and learning, one that paves the way for developing and maintaining professional mastery, via training, education and social learning. To achieve the full potential of such learning and knowledge development, individual variations in capabilities, learning styles, and idea generating bahaviour must be recognized, accepted, and allowed to flourish.

Trust is an underpinning factor in knowledge development and knowledge mobilization and it manifests itself in an acceptance of mistakes as learning events. It is also an essential element of willingness to share information. In fact, the sharing of information lies at the core of NCW. Sharing has an organizational, a behavioral, and a technical component. As stated earlier, while the technical component enables, the organizational and behavioral components generate value. 
Other crucial elements for learning and knowledge development are teamwork, cooperation and collaboration. For these elements to be successful, they must be based on common goals, social cohesion, common identity, mutual trust, and doctrine that reflect these values.

Although this paper focuses on the military force facing the challenges of working and operating in a network centric manner, the enabling processes describe din this paper are equally applicable to any organization operating in a climate of uncertainty and exposed to the vagaries of political and economic conditions.

\section{References}

Australian Defence Force. (2003). Australian Defence Force Network Centric Warfare Concept. 2.

Ahvenainen, S. (2003). Backgrounds and principles of network-centric warfare. Course of Network-Centric Warfare for Post-Graduate Students. National Defence College.

Ali, I., C. Pascoe, L. Warne. (2002). Yet another role for team building and work motivation-enabler of knowledge creation and knowledge sharing. 2002 Command \& Control Research \& Technology Symposium - C2Transformation Through Experimentation (CCRTS) $11^{\text {th }}-13^{\text {th }}$ June, 2002. Naval Postgraduate School, Monterey, CA. CCRP Publishing Proceedings (CD-ROM).

Barber, B. (1983). The logic and limits of trust. New Brunswick, N.J, Rutgers University Press.

Bovasso, G. (1992). A structural analysis of the formation of a network organisation. Group and organisation management, 17, 86-106. Sage Publishing.

Bowman, E. K. \& Pierce, L. G. (2003). Cultural barriers to teamwork in a multinational coalition environment. Proceedings of the $23^{\text {rd }}$ Army Science Conference. Retrieved from http://www.asc2002.com/summaries/i/IP-06.pdf

Chisholm, R. F. (1996). On the meaning of networks. Group and Organisational Management, 21, 216235. Sage Publishing.

Crawford, K. (2003). Factors affecting learning and communication in organizations: A paper commissioned by the Defence, Science and Technology Organisation, ESLA, FSAG, DSAD, DSTO. Creative Interactive Systems Pty Ltd.

Denison, D. R. (1996). What is the Difference between organizational climate? A native's point of view on a decade of paradigm wars. Academy of Management Review, 21 (3), 619(36).

Drucker, P. F. (1999a). Beyond the information revolution. The Atlantic Monthly, Oct 1999.

Drucker, P. F. (1999b). Managing oneself. Harvard Business Review, March-April, 65-74.

Erickson, P. E. (1979). The role of secrecy in complex organizations: From norms of rationality to norms of distrust. Cornell Journal of Social Relation, 14 (2), 121-138.

Gambetta, D. (1988). Can we trust, trust? In D. Gambetta (Ed.), Trust: Making and breaking cooperative relationships (pp.213-237). Oxford: Blackwell.

Guzley, R. M. (1992). Organizational climate and communication climate: predictors of commitment to the organization. Management Communication Quarterly, 5 (4), 379-402.

Jordan, B. (1996). From training to learning in the new economy. Rhodia Seminar on Employability, Sao Paulo, Brazil.

Kramer, R. M. (1999). Trust and distrust in organizations: Emerging perspectives, enduring questions. Annual Review of Psychology, 50, 569-598.

Lave, J. \& Wenger, E. (1991). Situated learning: Legitimate peripheral participation. Cambridge University Press.

Quinn, J. B. (1992). Intelligent enterprise. New York, New York: Free Press. 
Senge, P. M. (1990). The fifth discipline: The art \& practice of the learning organization. Random House.

Tucker, M. L. \& Meyer, G. D. (1996). Organizational communication: Development of internal strategic competitive advantage. Journal of Business Communication, 33 (1), 51-69.

Warne, L., Ali, I. \& Pascoe, C. (2003). Team building as a foundation for knowledge management: Findings from research into social learning in the Australian Defence Organisation, Journal of Information \& Knowledge Management, 2 (2), 93-106.

\section{Biographies}

Irena Ali is a Defence Scientist in DSTO. Ms Ali's background is in information management and information seeking. Her work focuses on researching organizational and cultural factors contributing to effective organizational learning and knowledge management. She has published and presented both nationally and internationally in the field of organizational and social learning. In her free time Irena is pursuing her culinary passion for hot and spicy and enjoys bush walking and snorkeling.

Dr. Leoni Warne is a Senior Research Scientist responsible for leading research in Enterprise Social Learning and Knowledge Management Architectures and the Human Dimension of Decision Processes. Dr Warne's research work is primarily focused on the social and organizational aspects of information systems. Her work has been presented in numerous international books, journals and conferences.

Derek Bopping has been part of DSTO since 1996. Currently, he is at a final stage of a PhD study at the School of Psychology, Australian National University. His research examines the social-psychological processes implicated in disclosure behaviour within the context of the Australian Defence Force. His broader interests concern the impact of ideology upon human socialidentity processes, and the psychology of organizational secrecy. A keen fisherman, Mr. Bopping holds a Bachelor of Arts majoring in Psychology and Sociology, and has masters' studies in Cognitive Science.

Dr Dennis Hart is a senior lecturer in the School of Business and Information Management. His academic and research interests centre on organizational aspects of information systems and information management. More specifically, he is interested in data and information ownership perceptions and their impact on information sharing behaviour as well as organizational politics and conflict surrounding systems development efforts. Non-academic interests centre on wine, operating his and his partner's vineyard, and learning to play his baby grand piano better, when time permits.

Celina Pascoe is a lecturer in Communication for Management at the University of Canberra, and a consultant for the Australian Department of Defence's Science and Technology Organisation (DSTO). She is currently undertaking her PhD on the relationship between knowledge sharing and organisational communication culture. Her specific focus is the role of workplace interpersonal communication in fostering open climates within large Australian government organisations. Other research interests include the role of communication satisfaction in optimising the knowledge generation and sharing capabilities of workplace communities of practice; the impact of the Internet on academic work; and the impact of information and communication technologies on job satisfaction and motivation. 